\title{
AMCP Partnership Forum: FDAMA Section 114-Improving the Exchange of Health Care Economic Data
}

\section{SUMMARY}

The Food and Drug Administration Modernization Act (FDAMA) of 1997 included Section 114 as a regulatory safe harbor with the goal of increasing the dissemination of health care economic information (HCEI) to those responsible for formulary decision making. HCEl is typically not included within FDA-approved labeling. Although it has been nearly 20 years since passage and enactment of Section 114, proactive distribution of HCEI has been underutilized by biopharmaceutical companies partly because of (a) vague wording in the statute and (b) the absence of FDA-implementing regulations. Consequently, companies and health care decisions makers have had to speculate about the scope of the provisions. As a result, the biopharmaceutical industry has significant concerns about stepping over the line when using the safe harbor. Also, payers and other "payer-like" decision makers (e.g., self-funded corporate insurers) who are trying to make appropriate coverage and utilization decisions are demanding this information but are not receiving it because of the uncertainties in the statute.

Considering this renewed interest by multiple stakeholders regarding the need for revisions and/or guidance pertaining to Section 114, the Academy of Managed Care Pharmacy held a partnership forum on March $1-2,2016$, with a diverse group of health care stakeholders to provide the FDA with considerations for disseminating a guidance document on current thinking for the sharing of HCEI with health care decision makers. Forum participants represented the managed care industry, biopharmaceutical industry, health care providers, pharmacoeconomic experts, policy experts, and patient advocacy groups with specific expertise in the development, use, and dissemination of HCEI. The multistakeholder group represented the key professionals and entities affected by the provisions of Section 114 and present the collective credibility necessary for Congress and the FDA to modernize and operationalize the safe harbor by using the consensus recommendations developed during the forum.

Speakers, panelists, and attendees focused on 4 terms in Section 114 that remain open to interpretation by companies and enforcement bodies: (1) the scope of HCEl, (2) the scope of "formulary committee or similar entity," (3) the definition of "competent and reliable scientific evidence (CRSE)," and (4) the parameters of how information "directly relates to an approved indication." Based on the forum results, it was recommended that the safe harbor for companies' proactive dissemination of information under Section 114 should include health care decision makers beyond health plan formulary committees, including organizations, or individuals in their role in an organization, who make health care decisions for patient populations. Recommendations also suggested expansion to organizations that evaluate HCEl or develop value frameworks and compendia and individuals in such organizations. Forum participants also recommended that HCEl be truthful, and not misleading, and be based on the expertise of professionals in the relevant area. HCEI must also be developed and disclosed in a transparent, reproducible, and accurate manner.

Forum participants also discussed and agreed on the types of information, format, and processes by which managed care pharmacy and other health care decision makers seek to receive HCEI from biopharmaceutical companies. Finally, participants encouraged the FDA, Congress, and other stakeholders to find ways to ensure that patients or their representative organizations have appropriate access to a full range of information about their medications and that information related to the medication pipeline is communicated to appropriate stakeholders in a timely manner.

J Manag Care Spec Pharm. 2016;22(7):826-31

Copyright $\odot 2016$, Academy of Managed Care Pharmacy. All rights reserved.

$\mathrm{H}$ ealth care economic information (HCEI) has long been valued by managed care organizations, payers, pharmacy benefit managers, and other entities that are responsible for drug formulary decision making for its assistance in evaluating the benefits and costs of drugs and health technologies. ${ }^{1}$ Nearly 20 years ago, Section 114 of the Food and Drug Administration Modernization Act (FDAMA) of 1997 was instituted to authorize the communication of HCEI between biopharmaceutical companies and formulary committees or similar entities. ${ }^{2}$ However, the U.S. Food and Drug Administration (FDA) has yet to release guidance or regulations to provide clarification on this topic; therefore, confusion remains regarding what is permissible under Section 114 , leaving interpretation of the statutory language unclear to individual companies and enforcement bodies.

Despite enactment of the law in 1997, proactive distribution of HCEI remains underutilized in large part because of biopharmaceutical companies' concerns that, given the absence of FDA regulations or guidance to clarify the boundaries of the safe harbor, providing economic analysis could result in FDA sanctions for off-label dissemination of information. ${ }^{1}$ As biopharmaceuticals become increasingly complex and personalized, and the U.S. health care system becomes increasingly focused on value and quality versus quantity, health care decision makers' evaluation of HCEI for these products is now more important than ever. For these reasons and others discussed in these proceedings, clarification and modernization of Section 114 and/or other laws regarding medical, scientific, and pharmacoeconomic information sharing is necessary to facilitate the communication of evidence for drugs and other health technologies.

\section{Purpose and Discussion Points}

To address the clarification and modernization of Section 114, the Academy of Managed Care Pharmacy (AMCP) held a partnership forum on March 1-2, 2016, with a diverse group of health care stakeholders to provide the FDA with considerations for disseminating a guidance document on current thinking for the sharing of HCEI with health care decision makers. 
The purpose of the forum was as follows:

1. Provide recommendations to the FDA (to the extent that the forum recommends expansion or change to the statutory safe harbor, then recommendations would be shared with the relevant congressional authorizing committees) for the promulgation of regulations or guidance to provide clarification and consistency of Section 114 requirements:

- Create definitions for the following terms referenced in Section 114 to clarify what is considered relevant HCEI:

a. Competent and reliable scientific evidence (CRSE).

b. Formulary committee or other similar entity.

c. HCEI.

d. Directly relates to an approved indication.

- Articulate the type of information, format, and process by which health care decision makers would like to receive HCEI from biopharmaceutical companies.

2. Consider whether Section 114, or other areas of existing laws and regulations, should be expanded to provide HCEI to additional entities and articulate the value that would be gained. Audiences for consideration include payers, health care providers, accountable care organizations (ACOs), integrated delivery networks (IDNs), patient advocacy groups (PAGs), organizations that develop value frameworks (e.g., American Society of Clinical Oncology [ASCO], National Comprehensive Cancer Network [NCCN], and Institute for Clinical and Economic Review [ICER]), and research societies (e.g., International Society for Pharmacoeconomics and Outcomes Research [ISPOR] and National Pharmaceutical Council [NPC]).

\section{Past, Present, and Future of FDAMA Section 114}

Speaker Peter Neumann, director of the Center for the Evaluation of Value and Risk in Health at Tufts Medical Center, opened the forum by providing an overview of the past, present, and future of Section 114. Government regulatory discussions of pharmaceutical promotion and health economic analyses by biopharmaceutical companies began in 1995. This time period also marked the rise of the field of pharmacoeconomics and outcomes research. Organizations that provide and house these types of analyses did not exist at this time. ISPOR, the organization now recognized for advancing the methods of pharmacoeconomics and outcomes research, was just coming into existence. Biopharmaceutical companies began examining what types of drug and health technology information could be actively promoted and in what manner. FDAMA included Section 114 to specify the conditions under which biopharmaceutical companies could promote HCEI.

Although it has been rumored for several years that the FDA would release guidance on Section 114, it has yet to do so. ${ }^{1}$ As the interest of managed care organizations, biopharmaceutical companies, and other entities in determining the value of health care interventions by using real-world evidence and comparative effectiveness research continues to increase, the need for clarity is now more important than ever. ${ }^{3}$ Many of the terms in Section 114 are not clearly defined in statute or regulations, including the scope of HCEI, the scope of "formulary committee or similar entity," the definition of "competent and reliable scientific evidence," and information included in the term "directly relates to an approved indication." Neumann and Saret (2015) developed hypothetical case studies of 10 categories of HCEI promotions to explore the potential legal and policy implications. These 10 categories included "(1) costing out on-label clinical end points; (2) promotion of a costing exercise to physicians working in an ACO setting; (3) burdenof-illness claims; (4) economic analysis of a formulary restriction policy; (5) extrapolations to doses, populations, or settings not covered in trials; (6) adherence claims; (7) 'utilization of care' as a secondary end point in randomized clinical trials; (8) costing out a competitor drug's adverse event; (9) economic analysis of comparative effectiveness claims using an indirect treatment comparison; and (10) extrapolating from surrogate to long-term outcomes in an economic model," all of which are prime examples of communications sought in the real world. ${ }^{4}$

Moving forward, managed care organizations, biopharmaceutical companies, and other entities are still seeking guidance documents or regulations from the FDA on Section 114. There is a high demand for broader interpretations of Section 114, formal guidance, and regulations, since multiple entities have the need for HCEI in formulary decision making. Additionally, the 21st Century Cures Act (H.R. 6), ${ }^{5}$ a bill intended to encourage medical innovation that passed the U.S. House of Representatives in July 2015, contains language that would expand Section 114. A few of these provisions include the following: (1) defining "health care economic information" to acknowledge that all HCEI contains clinical information and allowing companies flexibility around clinical and economic endpoints; (2) disclosure to allow for more transparency of health economic methodology including the analysis and inputs; (3) broadened language to specifically include payers, to suggest that HCEI is not only useful for formulary committees; and (4) "directly relates" was changed to "relates" to suggest that such extrapolations mentioned previously are allowed. Although the 21st Century Cures Act provides more clarity on HCEI, as the U.S. Senate considers similar legislation, it is not certain whether it will contain the language from the House bill. Further, forum participants agreed that while the 21st Century Cures Act was a step in the right direction, it did not provide the level of clarity needed to truly operationalize Section 114, absent guidance or regulations from the FDA. Therefore, it is essential that the FDA avoid any further delays in providing guidance on Section 114. 


\section{Current Challenges and Barriers}

Currently, significant uncertainties regarding many of the terms stated in Section 114 exist. Challenges and barriers outlined by forum panelists and participants include the following:

- What is the scope of HCEI that can be communicated? One main issue that arises with this statement is that health care economic analyses often contain clinical content, at least at the foundation; therefore, HCEI is not purely an economic claim.

- To whom does "formulary committee or similar entity" refer? Today, health care decision makers include entities that did not exist in 1997, including ACOs and IDNs. "Similar entity" seems to suggest all organizations involved in population health decisions, but this was never specified. Where is the line drawn?

- What constitutes CRSE and how does it differ from the traditional FDA evidentiary "substantial evidence" standard? Section 114 did not specifically define the evidentiary requirements for CRSE, although it is clear that this is a different standard than the "adequate and well-controlled" standard for inclusion of clinical trial information in the FDA-approved labeling. These requirements may include transparency of methodology through "good research practices" (defined by professional societies' guidelines for conducting research) and disclaimers about research and methods, among others. Although professional societies have developed research guideline reports that provide consensus on good research practices, there are many guideline reports from several different professional societies (e.g., ISPOR and AMCP) with guidelines that are not always consistent across reports.

- Does "directly relates" include modeling and extrapolating from intermediate to long-term endpoints or to other subgroups and doses? "Directly relates" seems to suggest that FDAMA 114 is not a vehicle to make HCEI claims beyond the approved indication and the populations or doses in clinical trials.

Given the significant gray areas in Section 114, the evolution of health care since 1997, and the growing need for HCEI by decision makers, clarifying guidance from the FDA is necessary.

\section{HCEI Under FDAMA Section 114}

In considering HCEI under Section 114, speakers and panelists discussed how evidence needs have changed since 1997, what constitutes HCEI, how it should be evaluated, and how it is used today. Since 1997, a greater variety of drug and health technologies, at a wider range of prices, have become available. Participants agreed to the following:

- Evidence should be used and shared to provide clarity regarding the value of drugs and other health technologies.

- HCEI includes much more than costs and refers to a broad set of information well beyond the classic randomized controlled trial with limited endpoints and small sample sizes.
HCEI includes health care utilization (e.g., hospitalizations and emergency department visits), patient benefits, adherence, endpoint extrapolations, quality of life, and adverse events, in addition to their associated costs.

- Methodology, inputs, and limitations should be transparent. When data are not available and modeling techniques are used, it should be communicated that these models may be used when data are not available but may be updated as information becomes available.

- Evaluation and review are necessary to ensure that scientific evidence is "competent and reliable." Some panelists and speakers suggested that an independent objective body should be responsible for developing consensus recommendations regarding what is considered "good research practice" for CRSE and updating those recommendations on a regular basis as new types of methods and analyses become available. Also mentioned was that HCEI should be evaluated and be made available for formulary decisions.

\section{Suggested Definitions and Rationale for FDA Guidance} and Regulation on Terms Used in the Existing Statutory Language of FDAMA Section 114

\section{"Competent and Reliable Scientific Evidence"}

Forum participants defined CRSE as "truthful and non-misleading tests, analyses, research, studies, models, or other evidence. Such evidence would be based on the expertise of professionals in the relevant area and be derived using methods that are transparent, disclosed, reproducible, accurate, and valid."

Rationale:

- The Federal Trade Commission's definition was used as a basis for the Section 114 definition, ${ }^{9}$ although there was considerable debate around removing "generally accepted" because it may inhibit the development and use of new studies or data collection methods. As long as innovative methods are transparent, disclosed, reproducible, accurate, and valid, some forum participants noted that CRSE would not need to be "generally accepted."

- "Truthful and non-misleading" was included to reiterate that evidence must be transparent. Although scientific evidence may be competent and reliable, there is still potential for it not to be truthful and to be misleading. In addition, given the constitutional protection for "truthful and non-misleading" communication, this standard should form the basis for permissible information sharing.

- Transparency and disclosure would be met by presenting a full report of the evidence, including the methods, population, and analytic plans, that would be available to decision makers. Additionally, some participants noted that decision makers sometimes request that models be left with them to download, audit, and test, to the extent that this is possible given existing federal fraud and abuse laws. 
- The term "reproducible" was a highly debated topic. Panelists and participants noted that a model's results may not be reproducible and including this term may inhibit the use of models. Others debated that the methods should be reproducible, but the results would not be because different data sources (inputs) likely produce different results.

- It was recommended by forum participants that an independent objective entity would be responsible for developing consensus recommendations regarding "good research practices," but this entity would not necessarily be responsible for vetting all HCEI to determine if it is CRSE. However, this independent objective body could be made available to vet HCEI as CRSE should manufacturers need guidance on whether their HCEI meet the standard for CRSE. This entity would consist of a multistakeholder collaborative of representatives from organizations such as AMCP, ISPOR, and NPC, which would conform to requirements under the Federal Advisory Committee Act (FACA). ${ }^{10}$

\section{"Formulary or Other Similar Entity"}

Panelists and participants defined "other similar entity" as "health care decision makers beyond health plan formulary committees, including organizations, or individuals in their role in an organization, who make health care decisions for patient populations and organizations that evaluate HCEI or develop value frameworks and compendia, including individuals in such organizations."

Rationale:

- Examples of "other similar entity" include payers, ACOs, IDNs, and actuaries; pharmacy and therapeutic committees; physician practices involved in risk-sharing arrangements; and organizations that develop compendia, pathways, and/ or value frameworks. Flexibility should exist to identify additional entities in the future as the health care environment continues to evolve and as new test models are developed and implemented, such as by the Centers for Medicare and Medicaid Innovation (CMMI).

- Participants debated the option of allowing "no limitations" on the definition of "similar entities" under Section 114, other than that this particular provision would exclude dissemination directly to consumers. Many participants and speakers emphasized that Section 114 is designed to affect decisions related to health care decision making for entities involved in population health and not in direct patient care; therefore, discussion on clarifications should be similarly limited.

- Participants debated whether PAGs should be included as an "other similar entity." Participants in favor of this option suggested that extremely sophisticated PAGs exist and can understand and interpret these data, as well as break the data down to a "patient level." Those not in favor defended the position that there is a potential for abuse as a promotional activity to consumers, and again, that this part of the statute describes the delivery of information designed to affect decisions on population health. Including PAGs as an "other similar entity" is discussed in greater detail later in this report (see the "Recommendations to Congress" section).

\section{"Health Care Economic Information"}

Panelists and participants defined HCEI as "any analysis that identifies, measures, or compares the economic, clinical, or quality of life consequences for any treatment. This includes the costs and resource utilization of a drug or health technology relative to another drug, health technology, or no intervention." Rationale:

- Examples of HCEI include comparative effectiveness research and real-world evidence data. Evidence is presented as a resource used to inform a decision but is not necessarily limited to economic information and includes health care utilization and/or costs.

- Comparative studies should be included under Section 114 as long as the comparator is the standard of care, which may or may not be on-label.

- Unbranded evidence, such as burden of illness claims, needs to be addressed, but perhaps in other laws/regulations, since real-world drug utilization consists of on- and off-label treatments.

\section{"Directly Relates to an Indication Approved"}

Panelists and participants defined "directly relates to an indication approved" as "information about a product that may vary from the parameters utilized in a randomized control trial, such as dosage forms, settings, or populations studied," as long as it is still used within the approved disease indication.

Rationale:

- Participants stated that "directly relates" refers to the indication section of the label but does not limit to expanding the population, dosage, or settings within the indication.

- Participants debated the interpretation of "directly" in "directly relates" within Section 114. Some argued that "directly" limits the inclusion of several key attributes of any economic analysis, such as long-term consequences and benefits. Others suggested that Section 114 should be used as a vehicle to describe the real-world use of drugs or therapeutic technologies in individuals only within an approved indication.

- Payers indicated the need for HCEI on pipeline products prior to FDA approval in order to build this information into forecasting and premiums.

\section{Format and Process by Which Managed Care Pharmacy Should Receive HCEl from Biopharmaceutical Companies \\ Format}

Forum participants discussed a format and process by which HCEI could be communicated between managed care organizations and biopharmaceutical companies. Participants discussed using AMCP as a means for housing HCEI. Some participants found AMCP's current dossiers to be an organized and comprehensive resource; however, other participants had little experience with the AMCP dossier process. Therefore, it was noted that this was one approach and one format, but other options exist. As mentioned previously, participants discussed 
the possibility of "leave-behind models" that would allow the health care decision maker or entity to download, audit, and test the models. This could also allow for decision makers to modify the assumptions of the model based on their perspectives and their covered populations. Health economic analyses would also be fully disclosed, meaning that bibliography, supporting documents, limitations, and potential biases would be fully detailed. Participants also suggested that leave-behind models might require a safe harbor to provide protection from allegations under the federal anti-kickback statutes associated with the potential that the leave-behind models are of value and could be viewed as potentially inappropriate inducements or incentives to the entity receiving the model. ${ }^{8}$

\section{Process}

Taking into consideration all definitions and the format outlined previously, many forum participants encouraged the institution of an objective independent body that would be responsible for developing "good research practice" guidelines for CRSE. Furthermore, participants suggested that a central repository could be implemented once HCEI became available. An alert system could notify covered parties when information is available in the repository to allow people to find promotional material of interest.

\section{Recommendations to Congress to Amend, Provide} Clarification, and/or Incorporate Possible Expansion of FDAMA Section 114 or Other Areas of Existing Laws

In addition to the definitions previously outlined, forum participants agreed that "directly relates" should be amended to "relates" under Section 114. "Relates" can also mean a drug or other health technology indication that is not specifically stated in the label. Claims regarding intended indications versus approved indications would have to be specifically addressed by the FDA to provide clarity on what is permissible under this part of Section 114. Furthermore, participants agreed that other amendments to Section 114 would include disclosures of transparency, expansion of additional entities under "other similar entity," and the agreed-upon format and process previously mentioned.

Furthermore, throughout the forum discussion it was discussed that there is need for the FDA and Congress to work together in finding a solution for possibly providing HCEI in 2 additional circumstances. First, because patients increasingly have an economic interest in the value of treatment decisions, there is a need for patients to be able to learn about HCEI in order to be an advocate for their own health care decisions. However, forum participants were cautious to recommend that this type of information be disseminated directly to consumers and debated the appropriate mechanism of making this information available to consumers, such as providing only to PAGs with a certain level of scientific expertise. While no consensus was reached, it was agreed that this area needs to be explored further and that appropriate patient protections would need to be addressed. Second, payers and other entities seek HCEI related to drugs and health care technologies in the pipeline 12-18 months before drug or technology approval. Early dissemination of HCEI would allow payers to build this information into forecasting and premiums, since waiting until approval is often too late. It was agreed that these are important areas of possible expansion for safe harbor, but it may not be within the spirit or original intent of Section 114. Therefore, further discussions in this area as to how other laws or regulations, such as expanding scientific exchange provisions, could be amended to provide this type of access to HCEI for PAGs and pipeline medications are warranted.

\section{Value of Expanding FDAMA Section 114}

Revisions or guidance to Section 114 are now more important than ever. Value is increasingly a critical element outlined by private payers and health and human services alike. As biopharmaceuticals become increasingly complex and personalized, and the U.S. health care system becomes increasingly focused on value, it is essential that product value is accurately measured through health economic analyses. Expanding Section 114 would also modernize the statute to align with today's health care system, which now includes a variety of entities, data sources, innovative models, and analytics that did not exist in 1997. Furthermore, expanding Section 114 as previously outlined would allow for better decision making in a collaborative spirit between patients, providers, payers, and other entities.

Information exchange across channels would facilitate a dialogue on the value of a product and further engage more indepth scientific exchange to address more accurate pharmacoeconomic evaluations. Furthermore, improved dissemination of HCEI to decision makers would drive higher value health care. In its current state, FDAMA Section 114 is too limiting and does not have these intended effects.

\section{Conclusions}

Guidance has long been sought by managed care organizations, payers, and drug formulary decision-making entities on FDAMA Section 114. The communication of HCEI is now more important than ever because the products available to treat conditions; available information sources; analytic processes; and the organization, delivery, and reimbursement of health care have vastly evolved in the past few decades. Therefore, now is the time for laws and regulations, even outside of Section 114, to evolve in parallel. The recommendations from this forum's participants to the FDA and Congress to amend, provide clarification to, or expand Section 114 will allow for better decision making in a collaborative environment and ensure appropriate regulatory governance of truthful and nonmisleading HCEI, without interfering with drug and health technology innovation. 


\section{Forum Participants}

YANJUN (CAROL) BAO, PhD, Senior Director, HCV, Health Economics and Outcomes Research, AbbVie; CHRISTOPHER MICHAEL BLANCHETTE, PhD, MBA, Vice President, Evidence Strategy and Generation, Precision Health Economics (panelist); LAURIE BURKE, RPh, MPH, Founder, Lora Group (panelist); LISA CASHMAN, PharmD, Director Clinical Formulary, MedImpact Health Care Systems (panelist); ELIZABETH J. COBBS, $P h D$, Executive Director, Center for Observational \& Real World Evidence, Merck \& Co.; GREGORY DANIEL, PhD, MPH, RPh, Deputy Director, Duke-Margolis Center for Health Policy (panelist); DAN DANIELSON, MS, RPh, Pharmacy Manager, Clinical Services, Premera Blue Cross (panelist); JEFFREY K. FRANCER, JD, MPP, Vice President and Senior Counsel, Pharmaceutical Research and Manufacturers of America (panelist); JENNIFER GRAFF, PharmD, Vice President, National Pharmaceutical Council (panelist); JOEL W. HAY, PhD, MS, MPhil, Professor, University of Southern California (panelist); J. RUSSELL HOVERMAN, MD, PhD, Vice President of Quality Programs, Texas Oncology, Medical Director, The U.S. Oncology Network (panelist); JAY JACKSON, PharmD, MPH, Vice President, Global Health Economics \& Outcomes Research, Xcenda; DANIEL C. MALONE, RPh, PhD, FAMCP, Professor, University of Arizona (panelist); JAMES K. MARTTILA, PharmD, MBA, Director, Pharmaceutical Contracting and Formulary Management, Mayo Clinic (panelist); CRAIG MATTSON, MS, $M B A, R P h$, Senior Director, Formulary Development, Prime Therapeutics; JOAN MCCLURE, MS, Senior Vice President of Clinical Information and Publications, National Comprehensive Cancer Network (panelist); JAY MCKNIGHT, PharmD, BCPS, Director, Clinical Strategies and Formulary Management, Humana (panelist); PHILIP NAUGHTEN, PharmD, Senior Director U.S. Research, Takeda Pharmaceuticals U.S.A.; PETER NEUMANN, SCD, Director, Center for the Evaluation of Value and Risk in Health, Tufts Medical Center (speaker); ELEANOR M. PERFETTO, PhD, MS, Professor, Pharmaceutical Health Services Research, School of Pharmacy, University of Maryland, Senior Vice President, Strategic Initiatives, National Health Council (panelist); CARLY RODRIGUEZ, PharmD, Manager, Clinical Pharmacy Services, OmedaRx; LAURIE WESOLOWICZ, PharmD, Director II, Pharmacy Services Clinical, Blue Cross Blue Shield of Michigan; RHYS WILLIAMS, MSc, DSc, Executive Director, Global Health Economics, Amgen; SUSAN C. WINCKLER, RPh, Esq., Chief Risk Management Officer, Leavitt Partners; LORI ZABLOW-SALLES, Esq., Executive Director, Executive Counsel, Boehringer Ingelheim Pharmaceuticals; and GERGANA ZLATEVA, PhD, Vice President, Payer Insights \& Access Lead, Oncology, Pfizer.

AMCP Staff: KEVIN BRUNS, JD, Vice President of Communications E Marketing; SUSAN A. CANTRELL, RPh, CAE, Chief Executive Officer; MARY JO CARDEN, RPh, JD, Vice President of Government \& Pharmacy Affairs; CHARLIE DRAGOVICH, BSPharm, Senior Director of Business Development $\&$ Strategic Alliances; TERRY RICHARDSON, PharmD, BCACP, Director of Product Development; and SOUMI SAHA, PharmD, JD, Assistant Director of Pharmacy \& Regulatory Affairs.

CORRESPONDENCE: Soumi Saha, PharmD, JD, Assistant Director of Pharmacy \& Regulatory Affairs, Academy of Managed Care Pharmacy, 100 N. Pitt St., Ste. 400, Alexandria, VA 22314.

E-mail: ssaha@amcp.org.

\section{DISCLOSURES}

The AMCP Partnership Forum on FDAMA Section 114-Improving the Exchange of Pharmacoeconomic Data and the development of this proceedings document were supported by AbbVie, Amgen, Boehringer Ingelheim Pharmaceuticals, Merck \& Co., National Pharmaceutical Council, Pharmaceutical Research and Manufacturers of America, Precision for Value, Pfizer, Takeda Pharmaceuticals, U.S.A., and Xcenda. All sponsors participated in the forum and participated in revising and approving the manuscript.

\section{ACKNOWLEDGMENTS}

The AMCP Partnership Forum on FDAMA Section 114-Improving the Exchange of Pharmacoeconomic Data was moderated by Susan Dentzer, President and CEO, The Network for Excellence in Health Innovation (NEHI) This proceedings document was written by Emily Zacherle, MS, Evidence Strategy and Generation, Precision Health Economics.

\section{REFERENCES}

1. Perfetto EM, Burke L, Oehrlein EM, Gaballah M. FDAMA Section 114: Why the renewed interest? J Manag Care Spec Pharm. 2015;21(5):368-74. Available at: http://www.jmcp.org/doi/abs/10.18553/jmcp.2015.21.5.368.

2. U.S. Food and Drug Administration. Food and Drug Administration Modernization Act (FDAMA) of 1997. Public Law 105-115. Available at: http://www.fda.gov/RegulatoryInformation/Legislation/Significant AmendmentstotheFDCAct/FDAMA/FullTextofFDAMAlaw/default.htm. Accessed May 23, 2016

3. Neumann PJ. Communicating and promoting comparative-effectiveness research findings. N Engl J Med. 2013;369(3):209-11.

4. Neumann PJ, Saret CJ. When does FDAMA Section 114 apply? Ten case studies. Value Health. 2015;18(5):682-89.

5. 21st Century Cures Act. H.R. 6. 114th Congress (2015-2016). Available at: https://www.congress.gov/bill/114th-congress/house-bill/6/text. Accessed May 23, 2016

6. Weinstein MC, O'Brien B, Hornberger J, et al. Principles of good practice for decision analytic modeling in health-care evaluation: report of the ISPOR Task Force on Good Research Practices-Modeling Studies. Value Health. 2003;6(1):9-17.

7. AMCP Format Executive Committee. The AMCP Format for Formulary Submissions. Version 3.1. December 2012. Available at: http://www.amcp.org/ practice-resources/amcp-format-formulary-submisions.pdf. Accessed May 23, 2016.

8. Criminal penalties for acts involving federal health care programs. 42 USC \& 1320a-7b (2009). Available at: https://www.gpo.gov/fdsys/granule/ USCODE-2009-title42/USCODE-2009-title42-chap7-subchapXI-partAsec1320a-7b. Accessed May 23, 2016.

9. Federal Trade Commission vs. Prolong Super Lubricants, Inc. Docket no. C-3906. November 22, 1999. Available at: https://www.ftc.gov/sites/default/ files/documents/cases/1999/11/prolong.do_.htm. Accessed May 23, 2016.

10. Federal Advisory Committee Act. Pub. L. No. $92-463$ (1972). Available at: https://www.gpo.gov/fdsys/pkg/STATUTE-86/pdf/STATUTE-86-Pg770. pdf. Accessed May 31, 2016. 